\title{
Quenched Bismuth Ferrite-Barium Titanate Lead-free Piezoelectric Ceramics
}

\author{
Ting Zheng and Jiagang $\mathrm{Wu}^{\mathrm{a})}$ \\ Department of Materials Science, Sichuan University, Chengdu, 610064, P. R. China
}

\begin{abstract}
In this work, the quenched method can effectively promote the electrical properties of bismuth ferrite-barium titanate $\left(\mathrm{BiFeO}_{3}-\mathrm{BaTiO}_{3}, \mathrm{BFO}-\mathrm{BTO}\right)$ ceramics. Here we mainly focused on the modification of the quenched methods in the $0.67 \mathrm{Bi}_{1.05} \mathrm{FeO}_{3}-0.33 \mathrm{BaTiO}_{3}$ ceramics with rhombohedral-cubic phase boundary. By optimizing the preparation conditions, the ceramics possess high Curie temperature $\left(T_{\mathrm{C}} \sim 457{ }^{\circ} \mathrm{C}\right)$, large piezoelectricity $\left(d_{33} \sim 170 \mathrm{pC} / \mathrm{N}\right)$, and good ferroelctricity $\left(P_{\mathrm{r}} \sim 22\right.$ $\mu \mathrm{C} / \mathrm{cm}^{2}$ ). The enhanced electrical properties are mainly assigned to the quenching technique with optimized conditions. We believe that such a systematic research can point out a way for further fabricating high-performance ceramics.
\end{abstract}

Keywords: $\mathrm{BiFeO}_{3}-\mathrm{BaTiO}_{3}$; Lead-free ceramics; Quenched method; Electrical properties

a) Corresponding author:

Email: msewujg@scu.edu.cn and wujiagang0208@163.com 


\section{Introduction}

$\mathrm{BiFeO}_{3}$ (BFO)-based ceramics were considered as one of high-temperature piezoelectric ceramics because of its good piezoelectricity $\left(d_{33}\right)$ and a high Curie temperature $\left(T_{\mathrm{C}}\right)$ [1]. Therefore, BFO-based ceramics have recently attracted considerable attention in order to realize the enhancement of electrical properties [2-26]. Site engineering [3-7] and the addition of second members [8-15, 18-21, 25-26] are the main methods to promote electrical properties of BFO-based ceramics. As far as ion substitution was concerned, it is difficult to attain the saturated polarization-electric field loops and enhanced piezoelectricity $\left(d_{33}>50 \mathrm{pC} / \mathrm{N}\right)$ due to high coercive filed and large leakage current [3-7]. However, the formation of solid solutions with other $\mathrm{ABO}_{3}$-type perovskite can greatly promote piezoelectric activity of $\mathrm{BFO}$ bulks, such as $\mathrm{BaTiO}_{3}[8-15,18-20,25-26], \mathrm{PbTiO}_{3}[16], \mathrm{SrTiO}_{3}$ [17], and so on [28-29]. Among these material systems, $\mathrm{BiFeO}_{3}-\mathrm{BaTiO}_{3}$ has been given considerable attention due to its high $T_{\mathrm{C}}$, relatively good $d_{33}$, and lead-free characteristics $[8-15,18-20,25-26]$.

In 2000 , the phase transformation of $(1-x) \mathrm{BiFeO}_{3}-x \mathrm{BaTiO}_{3}$ ceramics with variations of $x$ was investigated, and a rhombohedral-cubic (R-C) phase boundary was determined at $x=0.33$ [18]. In 2009 , both high $T_{\mathrm{C}}\left(\sim 619^{\circ} \mathrm{C}\right)$ and large $d_{33}(\sim 116 \mathrm{pC} / \mathrm{N})$ were reported in the $\mathrm{Mn}$-modified $0.75 \mathrm{BiFeO}_{3}-0.25 \mathrm{BaTiO}_{3}$ ceramics [12], and however some special preparation conditions (i.e., an oxygen atmosphere, the sintering aids, etc) were required [12]. Previously, it was reported that the quenched technique can effectively promote the electrical properties of BFO-based ceramics due to the great suppression of both oxygen vacancies and $\mathrm{Fe}^{2+}[3,9,19-20]$. However, there are few reports on the relationships between preparation process and electrical 
properties of BFO-BTO ceramics. In addition, the different preparation parameters also affect electrical properties of BFO-BTO ceramics $[12,19]$. Therefore, we mainly explored the influence of the quenched process on the microstructure and electrical properties of $0.67 \mathrm{Bi}_{1.05} \mathrm{FeO}_{3}-0.33 \mathrm{BaTiO}_{3}$ ceramics.

In this work, the $0.67 \mathrm{Bi}_{1.05} \mathrm{FeO}_{3}-0.33 \mathrm{BaTiO}_{3}$ ceramics were prepared by the quenched sintering method. Our objective is to investigate the relationships between quenched preparation parameters and electrical properties of the ceramics. The optimum electrical properties (i.e., $T_{\mathrm{C}} \sim 457{ }^{\circ} \mathrm{C}, d_{33} \sim 170 \mathrm{pC} / \mathrm{N}$, and $P_{\mathrm{r}} \sim 22 \mu \mathrm{C} / \mathrm{cm}^{2}$ ) can be exhibited. In addition, the saturated $P-E$ loops can be attained in the ceramics due to the quenching technique. The related physical mechanisms for enhanced electrical properties were also illuminated.

\section{Experimental procedure}

High-purity oxide powders $\left\{\right.$ e.g., $\mathrm{Bi}_{2} \mathrm{O}_{3}(99 \%), \mathrm{Fe}_{2} \mathrm{O}_{3}(99 \%), \mathrm{BaCO}_{3}(99 \%)$, and $\mathrm{TiO}_{2}$ $(98 \%)\}$ were used to prepare $0.67 \mathrm{Bi}_{1.05} \mathrm{FeO}_{3}-0.33 \mathrm{BaTiO}_{3}$ ceramics, where $5 \%$ mol of excess Bi was added to compensate for its volatility during the sintering process. All raw materials were weighted and ball milled for $24 \mathrm{~h}$ with alcohol. After that, the mixing slurries were dried and calcined at different calcined temperatures for $2 \mathrm{~h}$, and the calcined temperature is defined as $T_{\text {cal }}\left({ }^{\circ} \mathrm{C}\right)$. These calcined powders were mixed with a binder of $6 \mathrm{wt} \%$ polyvinyl alcohol (PVA) and then were pressed into pellets with $10 \mathrm{~mm}$ diameter and $0.6 \mathrm{~mm}$ thickness under a pressure of $10 \mathrm{MPa}$. After burning off PVA at $500{ }^{\circ} \mathrm{C}$ for $3 \mathrm{~h}$, the ceramics were sintered in air and then quenched in water. The sintering sketch graph is shown in Fig. 1. The initial sintering temperature, the sintering temperature, the dwell time, and the quenching temperature 
are defined as $T_{1}\left({ }^{\circ} \mathrm{C}\right), T_{\mathrm{S}}\left({ }^{\circ} \mathrm{C}\right), t_{\mathrm{S}}(\mathrm{h})$, and $T_{2}\left({ }^{\circ} \mathrm{C}\right)$, respectively. The heating and cooling rates are $10{ }^{\circ} \mathrm{C} / \mathrm{min}$. For characterizing electrical properties, all samples were pasted with silver plasma as electrodes and then fired at $600{ }^{\circ} \mathrm{C}$ for 10 minutes, and then a direct current electric field of $1 \sim 8 \mathrm{kV} / \mathrm{mm}$ was applied to the samples for 30 min in a silicon oil bath.

The phase structure of the ceramics was measured by X-ray diffraction (XRD) (Bruker D8 Advanced XRD, Bruker AXS Inc., Madison, WI, CuKa). The temperature dependence of capacitance and dielectric loss were measured using an $L C R$ analyzer (HP 4980, Agilent, U.S.A.) in the temperature range of $20 \sim 500{ }^{\circ} \mathrm{C}$. The surface microstructure was characterized by the field emission-scanning electron microscopy (FE-SEM) (JSM-7500, Japan). The polarization-electric $(P-E)$ hysteresis loops were measured by Radiant Precision Workstation (USA) at $f=100 \mathrm{~Hz}$ and room temperature, and $d_{33}$ was measured by piezo- $d_{33}$ meter (ZJ-3 A, China).

\section{Results and discussion}

\subsection{Calcined temperature vs. Properties}

In this part, we mainly investigated the effects of calcined temperature $\left(T_{\text {cal }}\right)$ on phase structure, microstructure, and electrical properties of 0.67BFO-0.33BTO ceramics, where $T_{1}, T_{\mathrm{S}}, t_{\mathrm{s}}$, and $T_{2}$ are respectively $700{ }^{\circ} \mathrm{C}, 990{ }^{\circ} \mathrm{C}, 3 \mathrm{~h}$, and $700{ }^{\circ} \mathrm{C}$, and the poling temperature $\left(T_{\mathrm{p}}\right)$ and poling electric field $(E)$ are $120{ }^{\circ} \mathrm{C}$ and $2.0 \mathrm{kV}$, respectively. Figure 2 shows the XRD patterns of the ceramics as a function of $T_{\text {cal }}$, measured at room temperature and $2 \theta=20 \sim 70^{\circ}$. All samples exhibit a pure perovskite structure, indicating the formation of a stable solid solution. Previously, it was reported that the phase structure of BFO-BTO ceramics can be identified by the 
selected peaks at $2 \theta=31 \sim 33^{\circ}$ and $38 \sim 40^{\circ}[8,14-15,18-19]$. As shown in Fig. 2, the ceramics without calcination exhibited a rhombohedral phase due to the splitted peaks of (110) and (111). It was reported that $(1-x)$ BFO- $x$ BTO ceramics with $x=0.33$ exhibited a morphotropic phase boundary (MPB) consisting of rhombohedral and pseudo-cubic phases [18]. As a result, the ceramics possess the R-C phase boundary as $T_{\text {cal }}$ increases $\left(\geq 500^{\circ} \mathrm{C}\right)$.

Figures 3(a) and (b) show the temperature dependence of dielectric constant $\left(\varepsilon_{\mathrm{r}}\right)$ and dielectric loss $(\tan \delta)$ of the ceramics with different $T_{\text {cal. }}$ As shown in Fig. 3(a), all curves have a sharp dielectric peak, which corresponds to their $T_{\mathrm{C}}$. A higher or lower $T_{\text {cal }}\left(0,500,850{ }^{\circ} \mathrm{C}\right)$ can lead to a much higher $\tan \delta$ in the region of high temperatures [See Fig. 3(b)]. In addition, all samples have a similar changing trend of $\tan \delta$ with varied temperatures, that is, $\tan \delta$ decreases firstly and then increases with the increase of measurement temperatures. When the temperature reaches about $200{ }^{\circ} \mathrm{C}$, a lower $\tan \delta$ value can be observed in the ceramics with $T_{\text {cal }}=600-800{ }^{\circ} \mathrm{C}$. Finally, the curve of $T_{\mathrm{C}}$ against $T_{\text {cal }}$ of the ceramics was shown in the inset of Fig. 3(a). One can find that $T_{\mathrm{C}}$ gradually increases and then decreases with rising $T_{\text {cal }}$, reaching a peak value for $T_{\text {cal }}=800{ }^{\circ} \mathrm{C}$. The varied $T_{\mathrm{C}}$ may be related to the composition fluctuations during calcination, especially for the loss of $\mathrm{Bi}$. As a result, it is very important to choose $T_{\text {cal }}$ for BFO-BTO ceramics.

Figure 4 shows the surface microstructure of the ceramics with $T=0,500,700$, and $850{ }^{\circ} \mathrm{C}$. We can see from Fig. 4 that a dense microstructure can be attained in all ceramics, and the grain sizes almost keep unchanged with the variations of $T_{\text {cal }}$, indicating that the calcined temperatures slightly affect the microstructure of the 
ceramics.

Figure 5(a) shows the effect of $T_{\text {cal }}$ on $P$-E loops of the ceramics, measured at room temperature and $f=100 \mathrm{~Hz}$. On can see from Fig. 5(a) that all ceramics have saturated $P-E$ loops. Figure 5(b) shows the remnant polarization $\left(P_{\mathrm{r}}\right)$ and piezoelectricity $\left(d_{33}\right)$ of the ceramics as a function of $T_{\text {cal }} . P_{\mathrm{r}}$ and $d_{33}$ firstly increase and then decrease as $T_{\text {cal }}$ rises, getting a maximum value $\left(P_{\mathrm{r}} \sim 22 \mu \mathrm{C} / \mathrm{cm}^{2}\right.$ and $\left.d_{33} \sim 170 \mathrm{pC} / \mathrm{N}\right)$ for $T_{\text {cal }}=700{ }^{\circ} \mathrm{C}$. As a result, the dielectric, ferroelectric, and piezoelectric properties of BFO-BTO ceramics can be enhanced by modifying the calcined temperature.

\subsection{Sintering condition vs. Electrical Properties}

In this part, the effects of sintering temperature $\left(T_{\mathrm{S}}\right)$ and dwell time $\left(t_{\mathrm{S}}\right)$ on phase structure, microstructure, and electrical properties of the ceramics were systematically studied. $T_{\text {cal }}$, initial sintering temperature $\left(T_{1}\right)$, and quenching temperature $\left(T_{2}\right)$ are fixed to be $700{ }^{\circ} \mathrm{C}$, and their $T_{\mathrm{p}}$ and $E$ are $120{ }^{\circ} \mathrm{C}$ and $2.0 \mathrm{kV}$, respectively. Figure 6(a) shows the XRD patterns of the ceramics sintered for $3 \mathrm{~h}$ as a function of $T_{\mathrm{S}}$, measured at room temperature and $2 \theta=20 \sim 70^{\circ}$. A pure perovskite structure can be obtained in all ceramics. As shown in Fig. 6(a), the ceramics sintered at $950{ }^{\circ} \mathrm{C}$ show a splitted peak of (110) and (111), and thus the phase structure can be defined as an R phase. A mixed phases appear with the increase of $T_{\mathrm{S}}$, as shown in the XRD patterns with $2 \theta=38 \sim 40$ ${ }^{\circ} \mathrm{C}$. Therefore, the R-C phase coexistence can be formed for $T_{\mathrm{S}}=965-1020{ }^{\circ} \mathrm{C}$. Figure 6(b) shows the XRD patterns of the ceramics sintered at $990{ }^{\circ} \mathrm{C}$ under different $t_{\mathrm{s}}$. As mentioned above, the R-C phase coexistence can be well established in the ceramics sintered at $990{ }^{\circ} \mathrm{C}$ for $3 \mathrm{~h}$. As shown in Fig. 6(b), $t_{\mathrm{s}}$ almost did not change the phase structure of the ceramics, indicating that a mixed phase still exists in the ceramics 
with different $t_{\mathrm{s}}$.

Figures 7(a) and (b) show the temperature dependence of $\varepsilon_{\mathrm{r}}$ and $\tan \delta$ of the ceramics sintered for $3 \mathrm{~h}$ under different $T_{\mathrm{S}}$, and $T_{\mathrm{C}}$ as a function of $T_{\mathrm{S}}$ was shown in the inset of Fig. 7 (a). $T_{\mathrm{C}}$ shifts to a low temperature as $T_{\mathrm{S}}$ increases up to $990{ }^{\circ} \mathrm{C}$ and then fluctuates in the vicinity of $460{ }^{\circ} \mathrm{C}$ with further increasing $T_{\mathrm{S}}$. It was previously reported that the grain sizes of the ceramics have a close relationship with $T_{\mathrm{C}}$, that is, the large grains can decrease $T_{\mathrm{C}}$ with respect to small grains $[8,22]$. Therefore, the relationships between $T_{\mathrm{C}}$ and grain size will be discussed later. In addition, a lower tan $\delta$ can be attained in the ceramics sintered in $965 \sim 1020{ }^{\circ} \mathrm{C}$ [See Fig. 7(b),]. Figures 7(c) and (d) show the temperature dependence of $\varepsilon_{\mathrm{r}}$ and $\tan \delta$ of the ceramics sintered at $990{ }^{\circ} \mathrm{C}$ with different $t_{\mathrm{s}}$, and $T_{\mathrm{C}}$ as a function of $t_{\mathrm{s}}$ was shown in the inset of Fig. 7(c). A decreased $T_{\mathrm{C}}$ can be observed for $t_{\mathrm{s}}=0.5-1 \mathrm{~h}$, and $t_{\mathrm{s}}$ slightly affects $\tan \delta$ [Fig. 7(d)].

Figure 8(a)-(f) shows the surface microstructure of the ceramics with different sintering temperatures and dwell time. One can observe from Fig. 8(a) that a small grain size can be observed in the ceramics with $T_{\mathrm{S}}=950{ }^{\circ} \mathrm{C}$. It can be found that the ceramics have the larger grain sizes with the increase of $T_{\mathrm{S}}$ [Fig. 8(b)]. In this work, the decreased $T_{\mathrm{C}}$ of the ceramics with $T_{\mathrm{S}}=950 \sim 990{ }^{\circ} \mathrm{C}$ should be due to the large grain sizes [8]. In addition, one can see from Figs. 8(b) and (c) that the grain sizes of the ceramics sintered at $990{ }^{\circ} \mathrm{C}$ and $1020{ }^{\circ} \mathrm{C}$ almost keep unchanged, which results in the slight changes of $T_{\mathrm{C}}$. The ceramics show a similar changing trend of grain sizes under different sintering temperatures [See Figs. 8(a) (f)]. A poor microstructure can be found in the ceramics sintered at $990{ }^{\circ} \mathrm{C}$ for $0.5 \mathrm{~h}$, and thus a higher $T_{\mathrm{C}}$ may be due to the presence of small grains [8]. However, the grains melt together when $t_{\mathrm{s}}$ is 
extended to $7 \mathrm{~h}$. As a result, the denser microstructure together with a larger grain size can be attained when both $T_{\mathrm{S}}$ and $t_{\mathrm{s}}$ increase. Interestingly, all ceramics sintered at $T_{\mathrm{S}}=990 \sim 1020{ }^{\circ} \mathrm{C}$ and $t_{\mathrm{s}}=3-7 \mathrm{~h}$ have a bimodal grain size distribution, that is, large and small grains simultaneously appear in the ceramics. With the increase of $T_{\mathrm{S}}$ and $t_{\mathrm{s}}$, the bimodal grain size distribution becomes more obviously. Previously, it was reported that an increase in the number of abnormal grains can be observed in the KNN-based ceramics doped with $\mathrm{Na}_{2} \mathrm{O}$ with the increase of sintering temperatures, and the increased $T_{\mathrm{S}}$ reduces the critical driving force needed for rapid grain growth and thus increases the number of abnormal grains [23-25].

Figures 9(a) and (b) show the $P-E$ loops of the ceramics as a function of $T_{\mathrm{S}}$ and $t_{\mathrm{s}}$. All samples show the typical $P-E$ loops. In order to show the variations of ferroelectricity and piezoelectricity with different $T_{\mathrm{S}}$ and $t_{\mathrm{S}}$, their $P_{\mathrm{r}}$ and $d_{33}$ as a function of $T_{\mathrm{S}}$ and $t_{\mathrm{s}}$ were shown in Figs. 9(c) and (d). As shown in Fig. 9(c), $P_{\mathrm{r}}$ and $d_{33}$ have a similar trend with the increase of $T_{\mathrm{S}}$, that is, $P_{\mathrm{r}}$ and $d_{33}$ quickly increase as $T_{\mathrm{S}}$ increases to 980 ${ }^{\circ} \mathrm{C}$ and then maintain a high value with further increase of $T_{\mathrm{S}}$. Optimum ferroelectric and piezoelectric properties $\left(P_{\mathrm{r}} \sim 22 \mu \mathrm{C} / \mathrm{cm}^{2}\right.$ and $\left.d_{33} \sim 170 \mathrm{pC} / \mathrm{N}\right)$ can be attained in a wide $T_{\mathrm{S}}$ range of $980 \sim 1010{ }^{\circ} \mathrm{C}$. As shown in Fig. 9(d), both $P_{\mathrm{r}}$ and $d_{33}$ of the ceramics sintered at $990{ }^{\circ} \mathrm{C}$ increase sharply when $t_{\mathrm{s}}$ extends from $0.5 \mathrm{~h}$ to $1 \mathrm{~h}$. After that, $P_{\mathrm{r}}$ and $d_{33}$ have a slight increase with further increase of $t_{\mathrm{s}}$, indicating that appropriate increase in $T_{\mathrm{S}}$ and $t_{s}$ can enhance electrical properties. The changing trend of $P_{\mathrm{r}}$ and $d_{33}$ with $T_{\mathrm{S}}$ and $t_{\mathrm{S}}$ is almost similar to other reported results [25]. Here, we explained the phenomenon about the changing trend of the ceramics with $T_{\mathrm{S}}$ and $t_{\mathrm{s}}$. Firstly, combined with the analysis of XRD and microstructure, the ceramics sintered at 950 ${ }^{\circ} \mathrm{C}$ for $3 \mathrm{~h}$ belong to be a $\mathrm{R}$ phase, and moreover a loose microstructure can be found 
in the ceramics sintered at $950{ }^{\circ} \mathrm{C}$ for $3 \mathrm{~h}$ and $990{ }^{\circ} \mathrm{C}$ for $0.5 \mathrm{~h}$. As a result, the $\mathrm{R}$ phase and the poor microstructure are the main reason to the poor electrical properties. In addition, the ceramics with $965 \sim 1020{ }^{\circ} \mathrm{C}$ and $1 \sim 7 \mathrm{~h}$ possess the $\mathrm{R}-\mathrm{C}$ phase coexistence together with a dense microstructure, thus leading to the enhanced electrical properties. Secondly, it was reported that the grain sizes can greatly affect the extrinsic contributions to the piezoelectric performance [26-27]. The domain mobility and reorientation can be limited by a strong coupling between domain walls and grain boundaries in the ceramics with small grain sizes, resulting in lower degree of polarization and poorer piezoelectric response [26, 27]. As a result, these factors (phase boundary, dense microstructure, and large grain size) can totally lead to the enhancement of electrical properties of this work.

\subsection{Quenching technique vs. Electrical Properties}

For BFO-based ceramics, the quenching technique is used to prepare the ceramics with excellent electrical properties [3, 9, 19-20]. However, there is almost no detailed exploration about quenching technique. Therefore, we systematically investigated the effects of quenching technique on phase structure, microstructure, and electrical properties of $0.67 \mathrm{BFO}-0.33 \mathrm{BTO}$ ceramics. $T_{\text {cal }}, T_{\mathrm{S}}$, and $t_{\mathrm{s}}$ are $700{ }^{\circ} \mathrm{C}, 700{ }^{\circ} \mathrm{C}$, and $3 \mathrm{~h}$, respectively. The ceramics were sintered at RT-990-RT with a slow heating rate of 3 ${ }^{\circ} \mathrm{C} / \mathrm{min}$ (non-quenched) for comparison. The XRD patterns of the ceramics with different initial sintering temperature $\left(T_{1}\right)$ and quenching temperature $\left(T_{2}\right)$ were shown

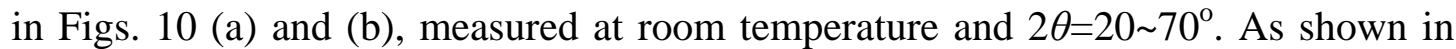
Fig. 10, a pure structure can be observed in all ceramics. One can find that the variations of $T_{1}$ and $T_{2}$ cannot induce the changes of phase structure, and thus all ceramics are still R-C mixed phases. 
Figures 11(a) and (b) show the temperature dependence of $\varepsilon_{\mathrm{r}}$ and $\tan \delta$ with different $T_{1}$, measured at $f=100 \mathrm{kHz}$, and $T_{\mathrm{C}}$ as a function of $T_{1}$ was shown in the inset of Fig. 11(a). Figures 11(c) and (d) show the temperature dependence of $\varepsilon_{\mathrm{r}}$ and $\tan \delta$ with different $T_{2}$, measured at $f=100 \mathrm{kHz}$, and $T_{\mathrm{C}}$ as a function of $T_{2}$ can be found in the inset of Fig. 11(c). As shown in Fig. 11(b), a much worse dielectric behavior can be observed in the ceramics with $T_{1}=\mathrm{RT}$ or RT-990-RT, showing that it is an useful way to reduce $\tan \delta$ in the high-temperature region by choosing higher $T_{1}$ and $T_{2} . T_{\mathrm{C}}$ is almost dependent on $T_{1}$ and $T_{2}$, while the dielectric peak of the ceramics with RT-990-RT shifts to a low temperature, as shown in Fig. 11(a). Therefore, the conventional solid-state method results in the composition fluctuations and thus $T_{\mathrm{C}}$ reduced.

Figures 12(a)-(f) show the surface microstructure of the ceramics with different quenched processes. All samples show a dense microstructure, and a bimodal grain size distribution can be found in the ceramics processed by the quenched method [Figs. 12(a) (e)]. However, a uniform grain size distribution can be observed in the ceramics by the normal sintering method, as shown in Fig. 12(f). As a result, the formation of bimodal grain size distribution is also partly due to the quenched process.

Figures 13(a) and (b) show the P-E loops of the ceramics with different $T_{1}$ and $T_{2}$. All ceramics sintered by the quenched method exhibit the saturated $P-E$ loops, while a roundish $P-E$ loop can be observed in the ceramics with RT-990-RT due to the involvement of a high leakage current, confirming that the quenched technique is an 
effective method to attain the saturated $P-E$ loops of BFO-BTO ceramics. Figures 13(c) and (d) show the effect of $T_{1}$ and $T_{2}$ on $P_{\mathrm{r}}$ and $d_{33}$ of the ceramics. $d_{33}$ slightly increases as both $T_{1}$ and $T_{2}$ increase, that is, higher $T_{1}$ and $T_{2}$ can slightly improve the $d_{33}$. In addition, the ferroelectricity treated by quenched technique can be well maintained. Some physical mechanisms have been used to unveil the improvement of piezoelectricity and ferroelectricity. The electrical properties of a piezoelectric material are related to the domain wall mobility, while the domain wall movement can be strongly prohibited by charged defects [20]. For the ceramics treated by quenched process, the disordered defect state can be freezed, and then their electrical properties can be enhanced [20]. As a result, the quenched technique is useful to promote $T_{\mathrm{C}}, d_{33}$, and $P_{\mathrm{r}}$ of BFO-BTO ceramics.

\subsection{Polarization condition vs. Electrical Properties}

Poling condition (i.e., poling temperature and electric field) is very important for the improvement of piezoelectricity in a ferroelectric ceramic. In this part, we studied the effects of $T_{\mathrm{p}}$ and $E$ on the piezoelectricity of $0.67 \mathrm{BFO}-0.33 \mathrm{BTO}$ ceramics, where $T, T_{1}$, $T_{\mathrm{S}}, t_{\mathrm{s}}, T_{2}$ are fixed to be $700{ }^{\circ} \mathrm{C}, 700{ }^{\circ} \mathrm{C}, 990{ }^{\circ} \mathrm{C}, 3 \mathrm{~h}, 700{ }^{\circ} \mathrm{C}$, respectively. Figure 14 (a) shows $d_{33}$ against $T_{\mathrm{p}}$ of the ceramics, measured at $E=2.0 \mathrm{kV}$. We can find from Fig. 14(a) that $d_{33}$ increases gradually with the increase of $T_{\mathrm{p}}$, illustrating that a high $T_{\mathrm{p}}$ can benefit the polarization rotation. Figure 14(b) gives $d_{33}$ against $E$ of the ceramics, measured at $T_{\mathrm{p}}=120{ }^{\circ} \mathrm{C}$. One can see from Fig. $14(\mathrm{~b})$ that $d_{33}$ increases sharply when $E$ increases from $0.5 \mathrm{kV}$ to $1.0 \mathrm{kV}$ and then maintains at a relatively stable value of $\sim 170 \mathrm{pC} / \mathrm{N}$ with further increase of $E$.

\section{Conclusion}


$0.67 \mathrm{Bi}_{1.05} \mathrm{FeO}_{3}-0.33 \mathrm{BaTiO}_{3}$ ceramics with $\mathrm{R}-\mathrm{C}$ phase boundary were fabricated by the quenched method, and the effects of preparation parameters on their phase structure, microstructure, and electrical properties were systematically investigated. High Curie temperature $\left(T_{\mathrm{C}} \sim 457{ }^{\circ} \mathrm{C}\right)$, large piezoelectricity $\left(d_{33} \sim 170 \mathrm{pC} / \mathrm{N}\right)$, and saturated $P-E$ loops $\left(P_{\mathrm{r}} \sim 22 \mu \mathrm{C} / \mathrm{cm}^{2}\right)$ were attained by optimizing the preparation conditions (e.g., $T_{\text {cal }}=700{ }^{\circ} \mathrm{C}, T_{\mathrm{s}}=990 \mathrm{oC}, t_{\mathrm{s}}=3 \mathrm{~h}, T_{1}=700{ }^{\circ} \mathrm{C}, T_{2}=700{ }^{\circ} \mathrm{C}, T_{\mathrm{p}}=120{ }^{\circ} \mathrm{C}$, and $E=2.0 \mathrm{kV} / \mathrm{cm}$ ). The enhancement of electrical properties may be due to the R-C phase boundary, optimized preparation process as well as quenched technique.

\section{ACKNOWLEDGMENTS}

Authors gratefully acknowledge the supports of the National Science Foundation of China (NSFC Nos. 51102173 and 51472169), and the College of Materials Science and Engineering of Sichuan University. Thank Ms. Hui Wang for measuring the SEM patterns. 


\section{References:}

1. Catalan G and Scott J F. Adv. Mater., 2009, 21(24), 2463-2485.

2. Pradhan A K, Zhang K, Hunter D, Dadson J B, Loutts G B. Bhattacharya P, Katiyar R. Zhang J, Sellmyer D J, Roy U N, Cui Y, Burger A. J. Appl. Phys., 2005, 97, 093903.

3. Zhang S T, Lu M H, Wu D, Chen Y F, and Ming N B. Appl. Phys.Lett., 2005, 87, 262907.

4. Yuan G L and Or S W, J. Appl. Phys. 2006, 100, 024109.

5. Jeon N, Rout D, Kim I W, and Kang S J L. Appl. Phys. Lett. 2011, 98, 072901.

6. Zheng T, Wu J. J. Mater. Chem. C, 2015, 3(15), 3684-3693.

7. Zheng T, Wu J. J. Mater. Chem. C, 2015, 3(43), 11326-11334.

8. Zheng Q J, Luo L L, Lam K H, Jiang N, Guo Y. Q, and Lin D. M. J. Appl. Phys. 2014, 116, 184101.

9. Lin Y, Zhang L L, Zheng W L, Yu J. J Mater Sci: Mater Electron., 2015, 26:7351-7360.

10. Zheng D G, and Zuo R Z. J. Am. Ceram. Soc., 2015, 98, 3670-3672

11. Chen J G, and Cheng J R. J. Am. Ceram. Soc., 2015, DOI: 10.1111/jace.14003.

12. Leontsev S O, and Eitel R E. J. Am. Ceram. Soc., 2009, 92[12], 2957-2961.

13. Yang H B, Zhou C R, Liu X Y, Zhou Q, Chen G H, Li W Z, Wang H. J. Euro. Ceram. Soc. 2013, 33, 1177-1183.

14.Yang S C, Kumar A, Petkov V, and Priya S. J. Appl. Phys.2013, 113, 144101.

15. Unruan S, Unruan M, Monnor T, Priya S., and Yimnirun R. J. Am. Ceram. Soc., 2015, 98, 3291-3298

16. Woodward D I, Reaney I M, Eitel R E, Randall C A. J. Appl. Phys., 2003, 94, 3313-3318. 
17. Ma Z Z, Tian Z M, Li J Q, Wang C H, Huo S X, Duan H N, Yuan S L. Solid State Sciences 2011, 13, 2196e2200.

18. Kumar M M, Srinivas A, Suryanarayana S V. J. Appl. Phys., 2000, 87, 855-862.

19. Kim D J, Lee M H, Park J S, Kim M H, Song T K, Kim, S W, Kim W J, Jang K W, Kim S S, Do D. J Electroceram., 2014, 33, 37-41.

20.Rojac T, Kosec M, Budic B, Setter N, and Damjanovic D. J. Appl. Phys., 2010, $108,074107$.

21. Yao Y B, Ploss B, Mak C L, Wong K H. Appl Phys A., 2010, 99: 211-216.

22. Hao J, Bai W, Li W, Zhai J. J. Am..Ceram. Soc., 2012, 95(6), 1998-2006.

23. Kim M S, Lee D S, Park E C, Jeong S J, Song J S. J. Euro.Ceram. Soc., 2007, 27, $4121-4124$.

24. Wu J G, Xiao D Q, Zhu J G. Chem. Rev., 2015, 115 (7), 2559-2595.

25.Lin D M, Zheng Q J, Li Y, Wan Y, Li Q, Zhou W. J. Euro. Ceram. Soc., 2013, 33, 3023-3036.

26. Zhou Q, Zhou C R, Yang H B, Chen G H, Li W Z, and Wang H. J. Am. Ceram. Soc., 2012, 95[12], 3889-3893.

27.Randall C A, Kim N, Kucera J P, Cao W, and Shrout T R. J. Am. Ceram. Soc., $1998,81,677-88$.

28. Ma Y, Chen X M. J. Appl. Phys., 2009, 105(5), 4107.

29. Wang Q Q, Wang Z, Liu X Q, Chen X M. J. Am. Ceram. Soc., 2012, 95(2), 670-675. 


\section{Figure captions}

Figure 1: The sintering sketch diagram of $0.67 \mathrm{BFO}-0.33 \mathrm{BTO}$ ceramics.

Figure 2: XRD patterns of the ceramics with different $T_{\text {cal }}$, measured at (a) $2 \theta=20-70^{\circ}$, (b) $2 \theta=21-23^{\circ}$, and (c) $2 \theta=38-40^{\circ}$

Figure 3: Temperature dependence of (a) $\varepsilon_{\mathrm{r}}$ and (b) $\tan \delta$ of the ceramics as a function of $T_{\text {cal }}$, and the inset in (a) is $T_{\mathrm{C}}$ against $T_{\text {cal }}$.

Figure 4: Surface microstructure of the ceramics with different $T_{\text {cal }}$.

Figure 5: (a) $P-E$ loops and (b) $P_{\mathrm{r}}$ and $d_{33}$ of the ceramics with different $T_{\text {cal }}$.

Figure 6: XRD patterns of the ceramics as a function of (a) sintering temperature and (b) dwell time

Figure 7: Temperature dependence of (a) $\varepsilon_{\mathrm{r}}$ and (b) $\tan \delta$ of the ceramics as a function of $T_{\mathrm{S}}$. Temperature dependence of (c) $\varepsilon_{\mathrm{r}}$ and (d) $\tan \delta$ of the ceramics as a function of $t_{\mathrm{s}}$. The insets in (a) and (c) are $T_{\mathrm{C}}$ against $T_{\mathrm{S}}$ and $t_{\mathrm{s}}$, respectively.

Figure 8: Surface microstructure of the ceramics with different $T_{\mathrm{S}}$ and $t_{\mathrm{s}}$.

Figure 9: $P-E$ loops of the ceramics with different (a) $T_{\mathrm{S}}$ and (b) $t_{\mathrm{s}}$, and $P_{\mathrm{r}}$ and $d_{33}$ of the ceramics as a function of (c) $T_{\mathrm{S}}$ and (d) $t_{\mathrm{s}}$.

Figure 10: XRD patterns of the ceramics as a function of (a) initial sintering temperature $\left(T_{2}=700{ }^{\circ} \mathrm{C}\right)$, and (b) quenched temperature $\left(T_{2}\right)\left(T_{1}=700{ }^{\circ} \mathrm{C}\right)$.

Figure 11: Temperature dependence of (a) $\varepsilon_{\mathrm{r}}$ and (b) $\tan \delta$ of the ceramics as a function of initial sintering temperature $\left(T_{1}\right) \quad\left(T_{2}=700 \quad{ }^{\circ} \mathrm{C}\right)$. The temperature dependence of (c) $\varepsilon_{\mathrm{r}}$ and (d) $\tan \delta$ of the ceramics as a function of quenching temperature $\left(T_{2}\right)\left(T_{1}=700{ }^{\circ} \mathrm{C}\right)$. The insets in (a) and (c) are $T_{\mathrm{C}}$ as a function of $T_{1}$ and $T_{2}$, respectively.

Figure 12: Surface microstructure of the ceramics with different $T_{1}$ and $T_{2}$.

Figure 13: $P-E$ loops of the ceramics with different (a) $T_{1}$ and (b) $T_{2}$, and $P_{\mathrm{r}}$ and $d_{33}$ 
of the ceramics as a function of (c) $T_{1}$ and (d) $T_{2}$.

Figure 14: $d_{33}$ of the ceramics as a function of (a) $T_{\mathrm{P}}$ and (b) $E$. 


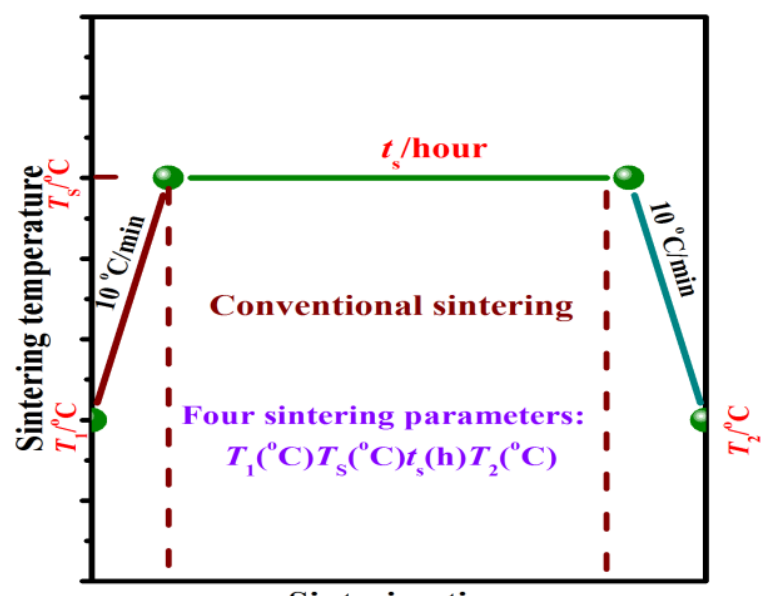

Sintering time

Figure 1 


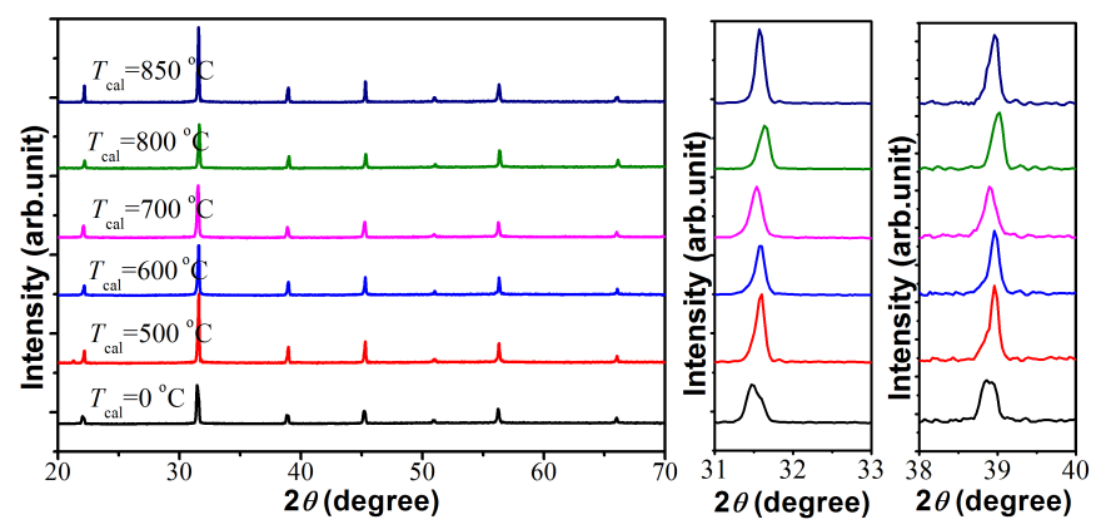

Figure 2 


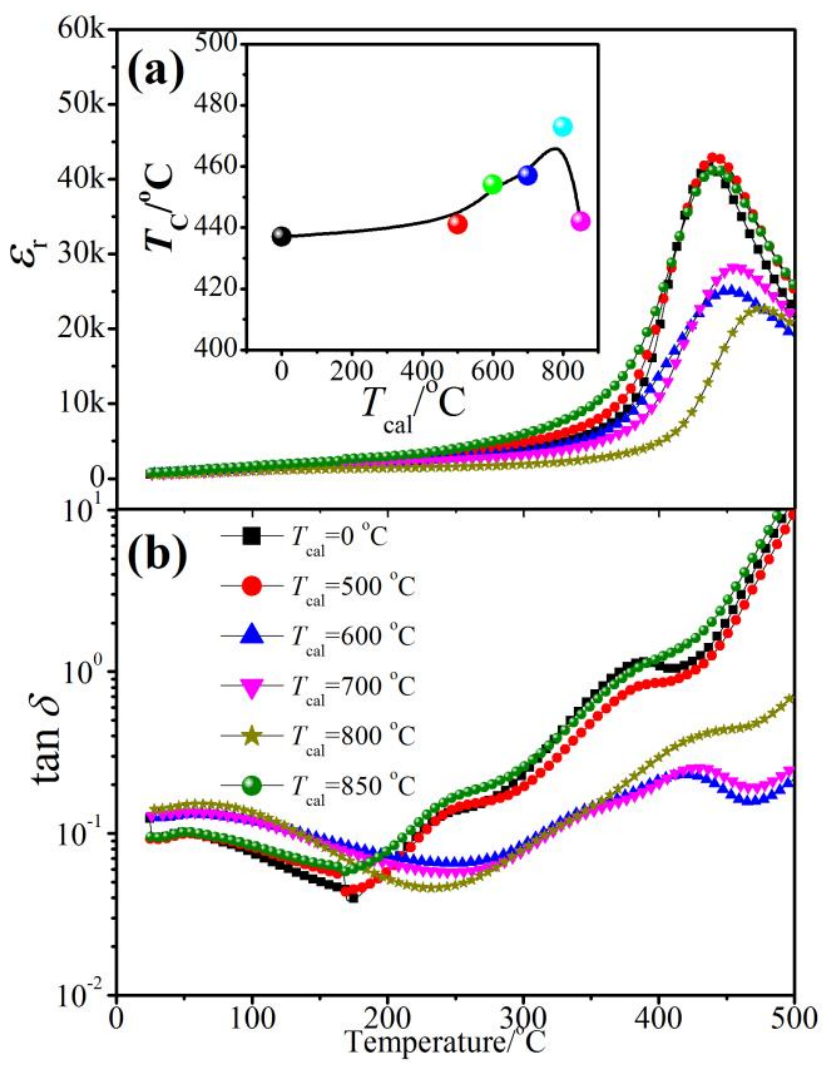

Figure 3 

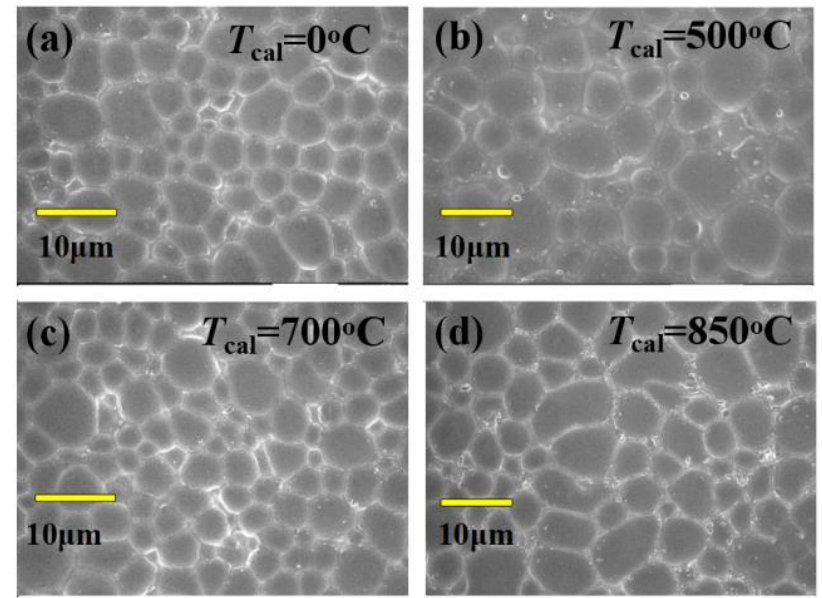

Figure 4 


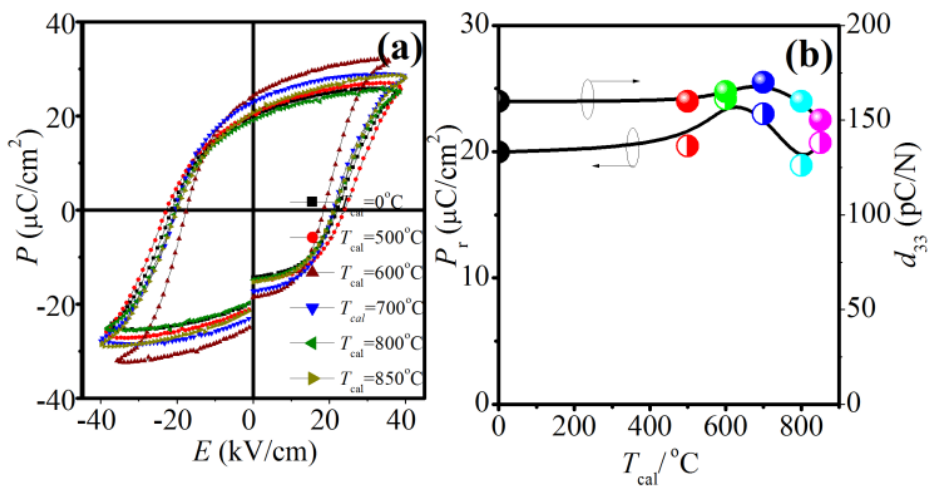

Figure 5 

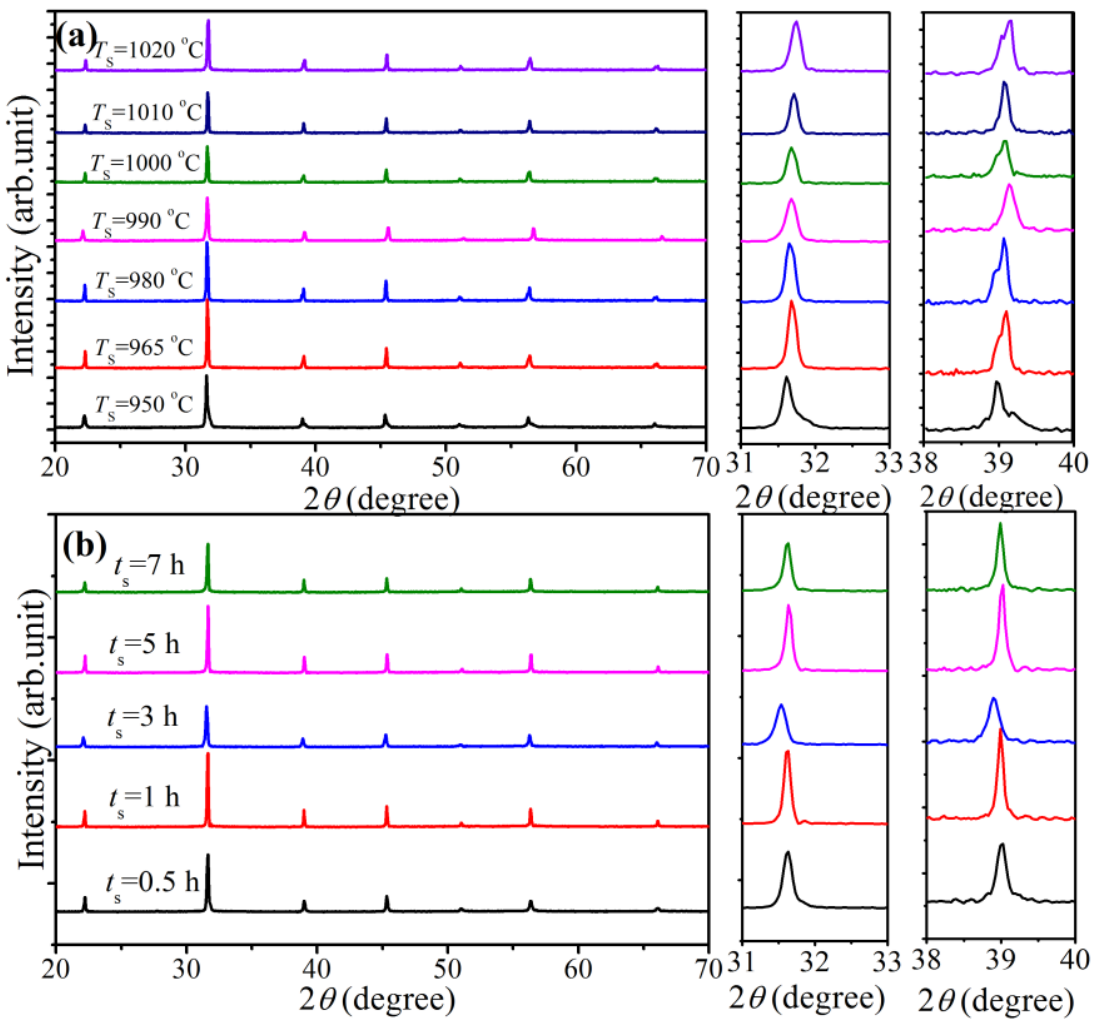

Figure 6 

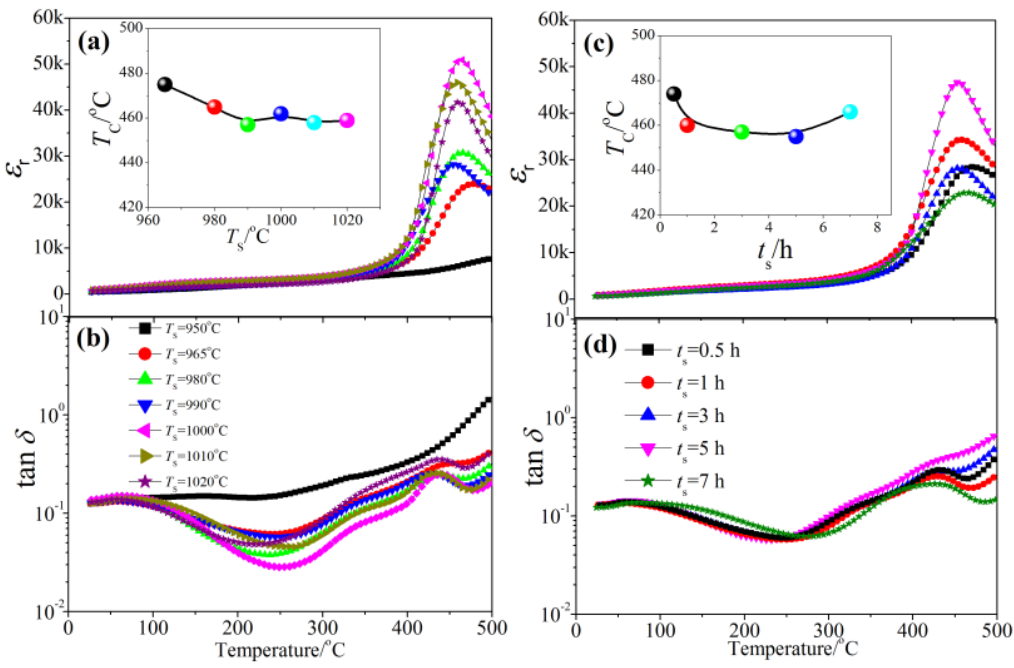

Figure 7 

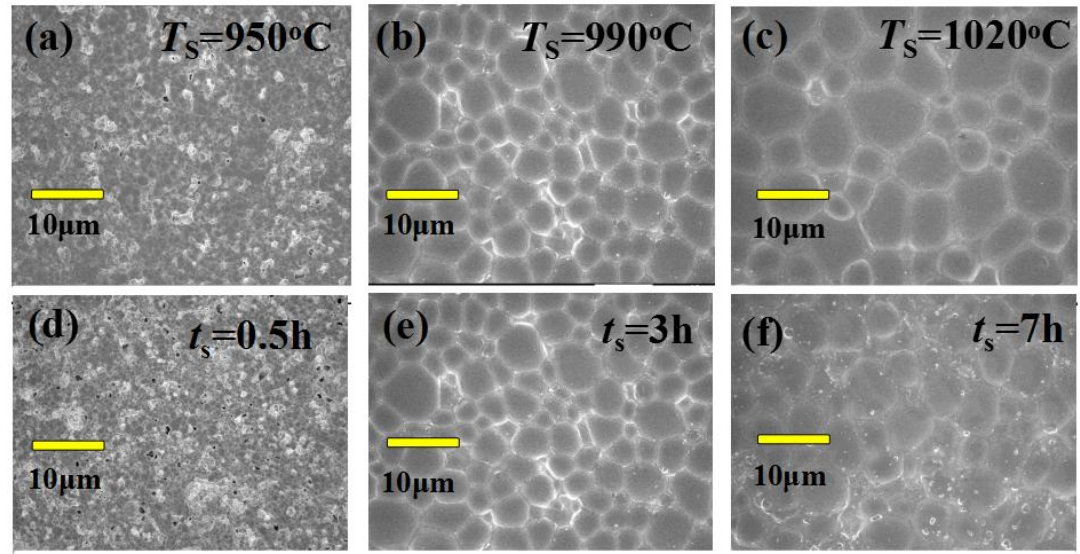

Figure 8 

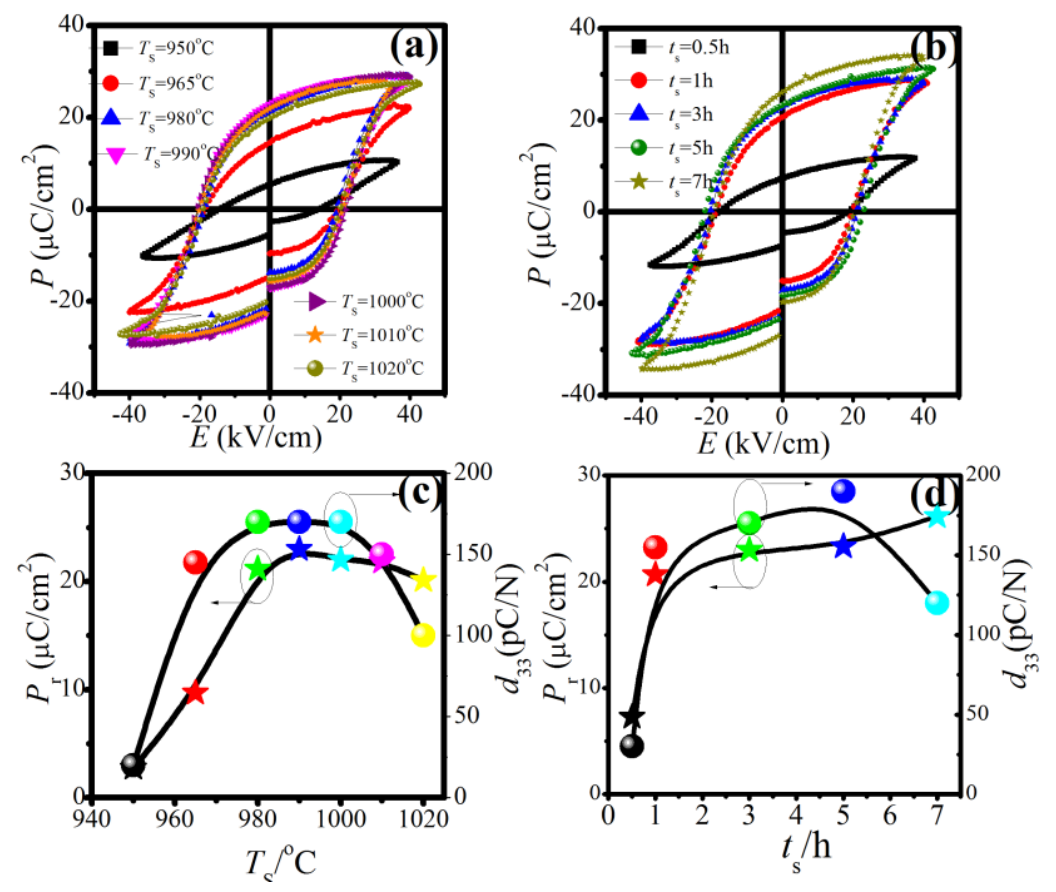

Figure 9 

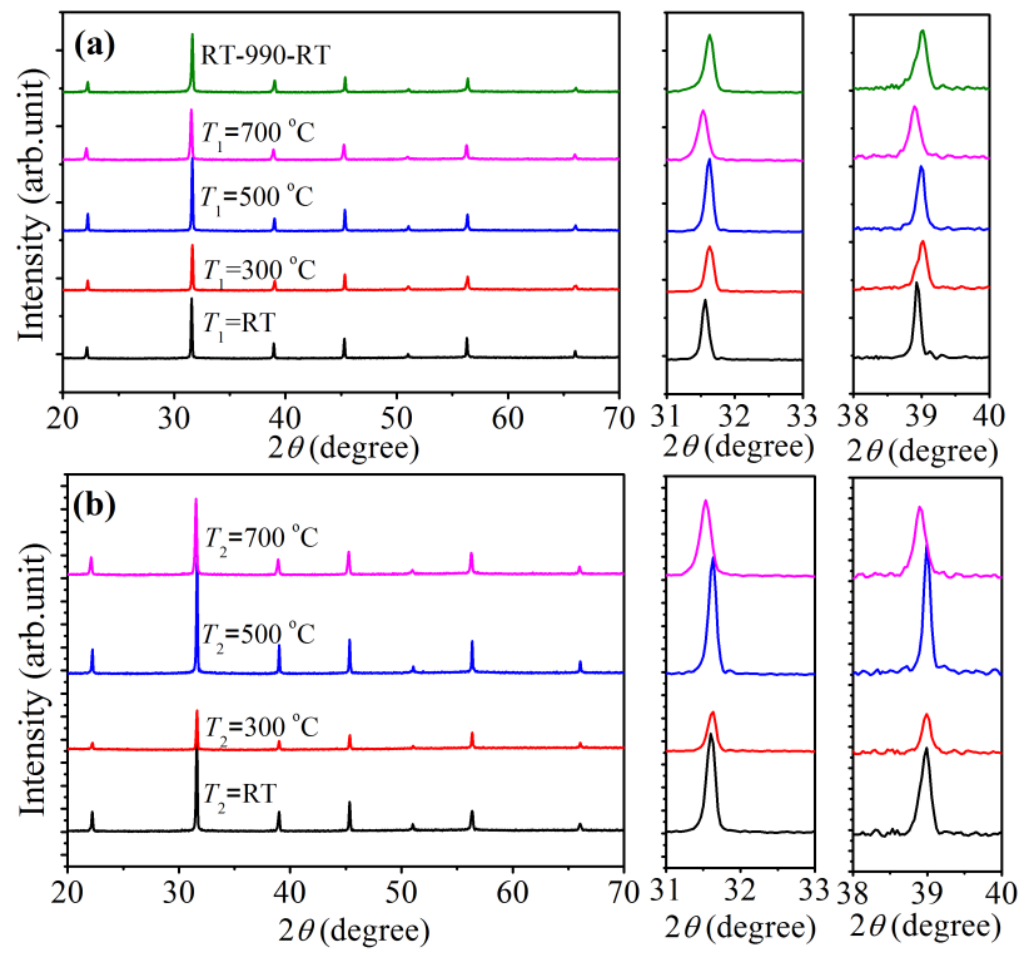

Figure 10 

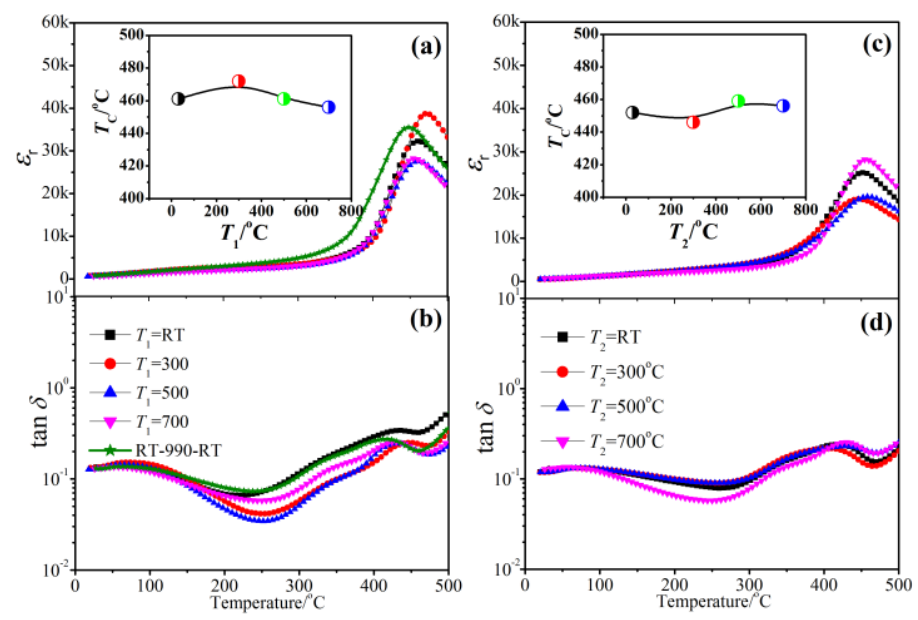

Figure 11 

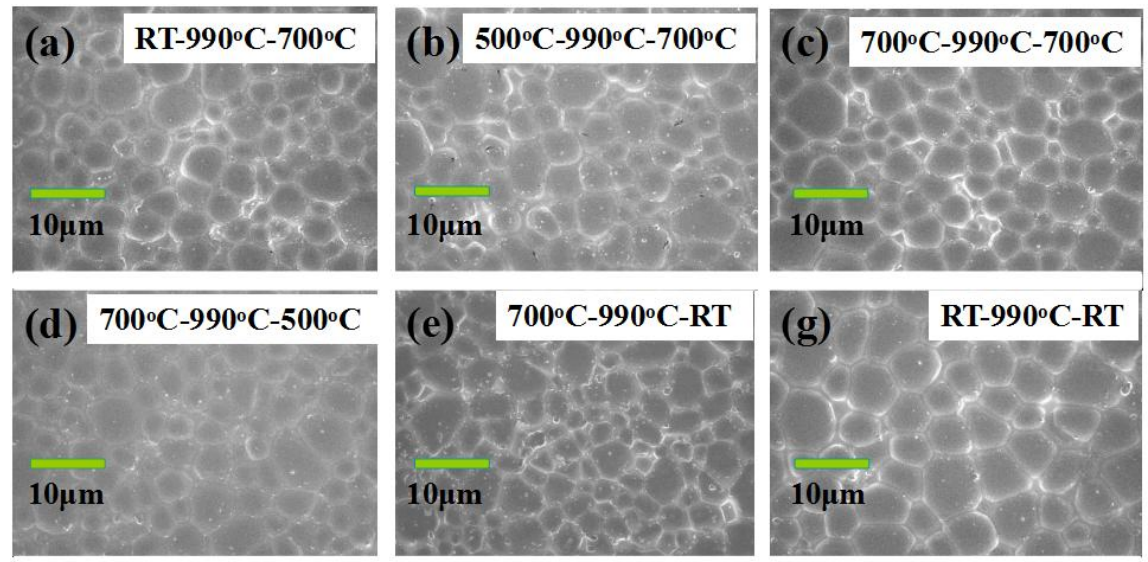

Figure 12 

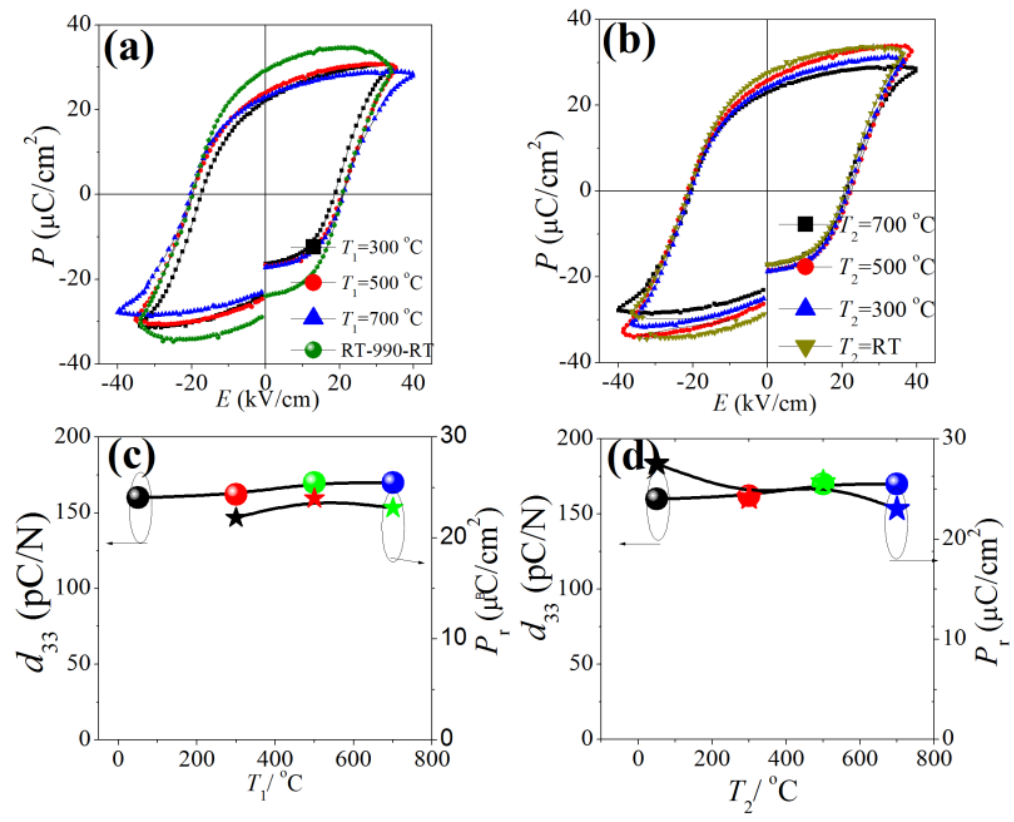

Figure 13 

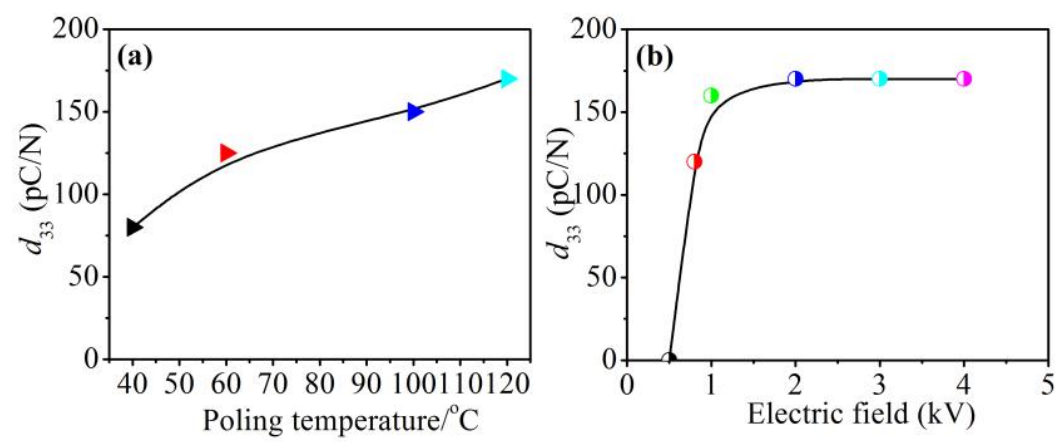

Figure 14 